\title{
PEEK (Polyether-ether-ketone) Based Cervical Total Disc Arthroplasty: Contact Stress and Lubrication Analysis
}

\author{
H. Xin, D.E.T. Shepherd* and K.D. Dearn
}

School of Mechanical Engineering, University of Birmingham, Edgbaston, Birmingham, B15 2TT, UK

\begin{abstract}
This paper presents a theoretical analysis of the maximum contact stress and the lubrication regimes for PEEK (Polyether-ether-ketone) based self-mating cervical total disc arthroplasty. The $\mathrm{NuNec}^{\circledR}$ cervical disc arthroplasty system was chosen as the study object, which was then analytically modelled as a ball on socket joint. A non-adhesion Hertzian contact model and elastohydrodynamic lubrication theory were used to predict the maximum contact stress and the minimum film thickness, respectively. The peak contact stress and the minimum film thickness between the bearing surfaces were then determined, as the radial clearance or lubricant was varied. The obtained results show that under $150 \mathrm{~N}$ loading, the peak contact stress was in the range 5.9-32.1 MPa, well below the yield and fatigue strength of PEEK; the calculated minimum film thickness ranged from 0 to $0.042 \mu \mathrm{m}$ and the corresponding lambda ratio range was from 0 to 0.052. This indicates that the PEEK based cervical disc arthroplasty will operate under a boundary lubrication regime, within the natural angular velocity range of the cervical spine.
\end{abstract}

Keywords: Cervical disc arthroplasty, contact stress, elastohydrodynamic, hertzain, lubrication, PEEK.

\section{INTRODUCTION}

This paper investigates important design parameters for PEEK (Polyether-ether-ketone) based self-mating cervical total disc arthroplasty. The human spine consists of a series of bony vertebrae that are separated by intervertebral discs, which consist of the inner nucleus pulposus and the outer annulus fibrosus [1]. The intervertebral disc is susceptible to degenerative diseases, nutritional deficiency, and ageing. A dysfunctional intervertebral disc can lead to spinal pain with a limited degree of motion [2].

There are generally two types of treatments for medium to severe neck pain: fusion surgery (FS) and motion preservation implantation, such as total disc arthroplasty (TDA). FS is considered as the 'gold standard' which can successfully relieve pain, however the spinal motion is also removed at the operation level. The primary aim of utilizing TDA is to restore pain-free motion [3]. Cervical TDA is a relatively new technology and there is much debate as to whether its performance is superior to that of fusion [4-7].

A number of cervical total disc implants that have been approved for use in patients including [3]:

- Bryan (Medtronic Sofamor Danek, Memphis, TN, USA) - Polyurethane against Titanium bearing coupling;

- Prestige (Medtronic Sofamor Danek, Memphis, TN, USA) - Stainless steel or Titanium ceramic composite self-mating bearing;

\footnotetext{
*Address correspondence to this author at the School of Mechanical Engineering, University of Birmingham, Edgbaston, Birmingham, B15 2TT, UK. Tel: +44 121414 4266; Fax: +44 121414 3958;

E-mail: d.e.shepherd@bham.ac.uk
}

- $\quad$ Prodisc-C (Synthes, Paoli, PA, USA) - Ultra High Molecular Weight Polyethylene (UHMWPE) against Cobalt Chromium Molybdenum alloy (CoCrMo) bearing coupling;

- $\quad$ PCM (Cervitech, Rockaway, NJ, USA) - UHMWPE against $\mathrm{CoCrMo}$ bearing coupling.

Among these current designs, the ball and socket design configuration dominates. Different material combinations have been used under this configuration to achieve the best tribological and fatigue outcomes; however some degree of inherent deficiencies or defects still exists for these combinations. Metal implants such as the Maverick lumbar disc can release metal ions (cobalt and chromium) in the form of wear debris. This detritus can cause localised tissue ion accumulation and eventually lead to cell death at excessive concentrations [8,9]. This is also expected to happen in metal based cervical discs, since wear is an inevitable consequence of normal function. Polymer joint implants (e.g. Ultra High Molecular Weight Polyethylene) generate wear debris which can provoke an adverse biological response (i.e. inflammation), and stimulate osteolysis which finally leads to implant loosening $[10,11]$. With the intention of overcoming the above shortcomings, new bearing materials have been introduced. PEEK (Polyether-ether-ketone) is one such material with great potential for cervical total disc replacement. However, its full performance needs to be analysed to investigate if it overcomes the problems of other material combinations. PEEK is a semi-crystal (i.e. having both amorphous and crystal phases) thermoplastic of the poly-aryl family. The aromatic backbone (i.e. benzene rings) is interconnected by the ether and ketone functional groups. This kind of chemical structure, generally shows high radiation and thermal ageing resistance with good mechanical and 


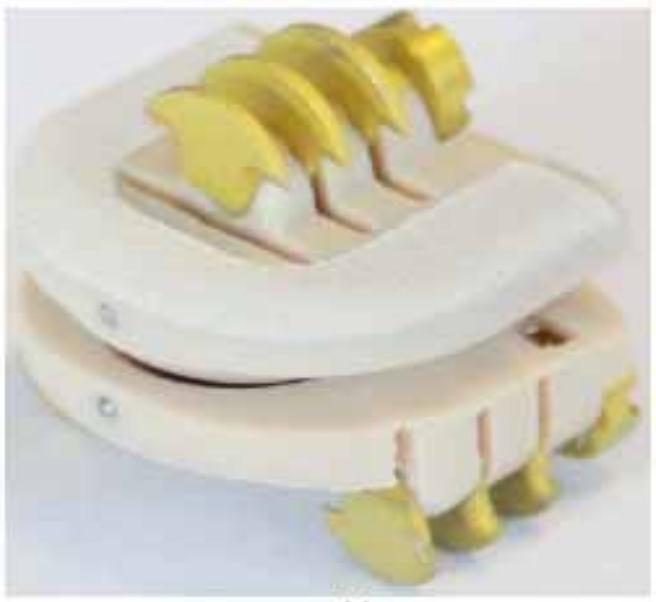

(a)

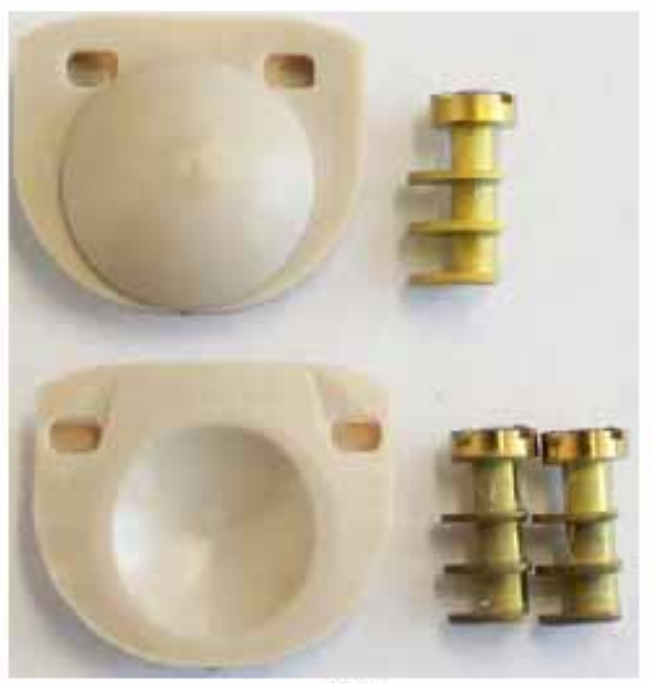

(b)

Fig. (1). The $\mathrm{NuNec}^{\circledR}$ cervical arthroplasty system a) assembled; b) unassembled.

tribological performance [12]. The overall aim of this study was to use theoretical analysis to investigate the maximum contact stress and lubrication regime of PEEK based cervical TDA.

\section{MATERIALS AND METHODS}

\subsection{Model}

The NuNec ${ }^{\circledR}$ cervical disc arthroplasty (Pioneer Surgical Technology Inc., Driebergen, Netherlands) was selected as the candidate TDA for this study. The smallest available footprint was chosen with the intention of replicating the worst case operational scenario. This cervical prosthesis consisted of two parts made from PEEK only, and adopted the conventional ball-on-socket design configuration as shown in Fig. (1). A unique cam fixation design is used for immediate short-term fixation, whereby metal blades extend from the device to grip the bone.

The TDA was modelled as a ball-and-socket joint with the ball having a radius $R_{1}$ and socket having a radius of $R_{2}$. The Young's modulus and Poisson's ratio for both the ball and socket was $E$ and $\nu$, respectively. The radial clearance $c$ between the ball and socket was defined as:
$c=R_{2}-R_{1}$

\subsection{Contact Stress}

A Hertzian fully elastic contact model was employed to analyze the maximum superficial contact stress between the bearing surfaces, assumed to be smooth, along with a negligible adhesion force between the contact zone [13, 14]. The maximum contact stress between the bearing surfaces was determined from:

$P_{\max }=\left[\frac{6 F \mathrm{E}^{2}}{\pi^{3} R^{2}}\right]^{\frac{1}{3}}$

where $F$ is the applied force, $E^{\prime}$ is the equivalent elastic modulus for the two bearing materials and $R$ is the equivalent radius for ball and socket. These two parameters were calculated from:

$E^{\prime}=\frac{E}{2\left(1-v^{2}\right)}$

and

$R=\frac{R_{1}\left(R_{1}+c\right)}{c}$

\subsection{Lubrication Regime}

The Hamrock-Dowson formula was used to predict the minimum film thickness $\left(h_{\min }\right)$ between the bearing surfaces and given as $[15,16]$ :

$h_{\min }=2.8 R\left(\frac{\eta u}{E^{*} R}\right)^{0.65}\left(\frac{F}{E^{*} R^{2}}\right)^{-0.21}$

where $E^{*}$ is the equivalent modulus of elasticity and $u^{u}$ is the entraining velocity. These two parameters were calculated from:

$E^{*}=\frac{E}{\left(1-v^{2}\right)}$

and

$u=\frac{\omega R_{1}}{2}$

From these values, the lubrication regime was predicted by calculating the lambda ratio:

$\lambda=\frac{h_{\min }}{\sigma}$

where $\sigma$ is the compound surface roughness given by:

$$
\sigma=\sqrt{R_{a 1}^{2}+R_{a 2}^{2}}
$$

where $R_{\mathrm{a} 1}$ and $R_{\mathrm{a} 2}$ are the mean surface roughness of the bearing surfaces for the ball and socket, respectively. If the lambda ratio is greater than 3 , then a fluid film lubrication regime occurs and complete separation of the bearing surfaces is achieved. A lambda ratio of less than unity indicates boundary lubrication and substantial contact 
Table 1. Summary of Parameters Used in the Analysis

\begin{tabular}{|l|c|c|}
\hline \multicolumn{1}{|c|}{ Parameter } & $\begin{array}{c}\text { Constant } \\
\text { Value }\end{array}$ & Range \\
\hline \hline Load, $F(\mathrm{~N})$ & 150 & $0-150$ \\
\hline Radius of ball, $R_{1}(\mathrm{~mm})$ & 6.3 & - \\
\hline Angular velocity, $\omega(\mathrm{rad} / \mathrm{s})$ & - & $0-4.5$ \\
\hline Radial clearance, $c(\mathrm{~mm})$ & 0.7 & $0.05-0.70$ \\
\hline Young's modulus, $E^{\prime}(\mathrm{GPa})$ & 3.7 & - \\
\hline Poisson's ratio, $\nu$ & 0.36 & - \\
\hline Viscosity, $\eta(\mathrm{mP} \cdot \mathrm{S})$ & $0.9,1.24$ & - \\
\hline Mean surface roughness of ball, $R_{\mathrm{a} 1}(\mu \mathrm{m})$ & 0.585 & - \\
\hline Mean surface roughness of socket, $R_{\mathrm{a} 2}(\mu \mathrm{m})$ & 0.525 & - \\
\hline Compound surface roughness, $\sigma(\mu \mathrm{m})$ & 0.786 & - \\
\hline
\end{tabular}

between surface asperities will occur. A lambda ratio of between 1 and 3 indicates a mixed-lubrication regime.

\subsection{Parameters}

The radii of the ball and socket of the NuNec ${ }^{\circledR}$ cervical disc arthroplasty were measured using a DEA-Swift coordinate measuring machine (CMM) (Hexagon Metrology Ltd., Telford, UK). The principle of the CMM was based on using a $2 \mathrm{~mm}$ diameter probe to take 15 randomly selected points across the whole bearing surface of the specimen. The collected data points were then computationally reconstructed to generate the profile of the specimen. Eight repeated measurements were taken for the ball and five repeated measurements were taken for the socket. The socket was found to have a mean radius of $7.010 \pm 0.022 \mathrm{~mm}$ and the ball had a radius of $6.307 \pm 0.004 \mathrm{~mm}$. For analysis the ball radius was chosen as $6.3 \mathrm{~mm}$ and the socket radius was chosen as $7 \mathrm{~mm}$, thus giving a radial clearance of $0.7 \mathrm{~mm}$. In this study the aim was to understand the effect of different radial clearances on stress and lubrication regime, so as well as a radial clearance of $0.7 \mathrm{~mm}$, radial clearances of $0.05,0.1$ and $0.15 \mathrm{~mm}$, which have been used by other investigators
[17-19], were also used in the analysis. Surface roughness of the bearing surfaces was measured using a Taylorsurf-120L (Taylor Hobson Ltd., Leicester, UK) profilometer with a 2 $\mu \mathrm{m}$ radius diamond stylus and an examining area of $5 \times 5$ mm. Talymap universal 3.1.8 (Taylor Hobson Ltd., Leicester, UK) equipped with a Gaussian filter (cut-off length $0.08 \mathrm{~mm}$ ) was used to manipulate the data and hence remove measurement noise. The obtained arithmetic mean surface roughness was found to be $0.585 \mu \mathrm{m}$ for the ball and $0.525 \mu \mathrm{m}$ for the socket, respectively. The corresponding compound surface roughness value (Eq. 9) was calculated to be $0.786 \mu \mathrm{m}$.

The angular velocity for the human cervical spine has been reported to be in the range of 0 to $4.5 \mathrm{rad} / \mathrm{s}$ [20]. This can be easily converted into an entraining velocity using Eq. 7. Interstitial fluid was proposed as the natural lubricant for the intervertebral disc, however bovine serum which is normally used for in-vitro wear testing of disc replacements was also considered [21]. An interstitial fluid with a viscosity of $1.24 \mathrm{mPa} \cdot \mathrm{s}$ was considered as the primary lubricant $[22,23] ; 25 \%$ bovine serum (diluted with deionised water) with a viscosity of $0.9 \mathrm{mPa} \cdot \mathrm{s}$ was used as a comparison [16, 24]. For this study, the maximum compressive loading for the cervical disc was assumed to be $150 \mathrm{~N}$, selected according to the recommended value from the ISO 18192-1 standard for testing intervertebral disc prostheses [21]. The Young's modulus $(E)$ and Poisson's ratio $(v)$ of PEEK were taken to be $3.7 \mathrm{GPa}$ and 0.36 , respectively $[12,25]$. Finally, the radial clearance was investigated in the range $0.05,0.1,0.7 \mathrm{~mm}$ and $0.15 \mathrm{~mm}$, while other design parameters were kept constant. A summary of the parameters used are shown in Table $\mathbf{1 .}$

\section{RESULTS}

\subsection{Contact Stress}

Fig. (2) shows the variation of maximum contact stress with force for TDA with different radial clearances. For a PEEK cervical disc under $150 \mathrm{~N}$ loading, the maximum contact stress is in the range 5.9 (for a radial clearance of $0.05 \mathrm{~mm}$ ) to $32.1 \mathrm{MPa}$ (for a radial clearance of $0.7 \mathrm{~mm}$ ).

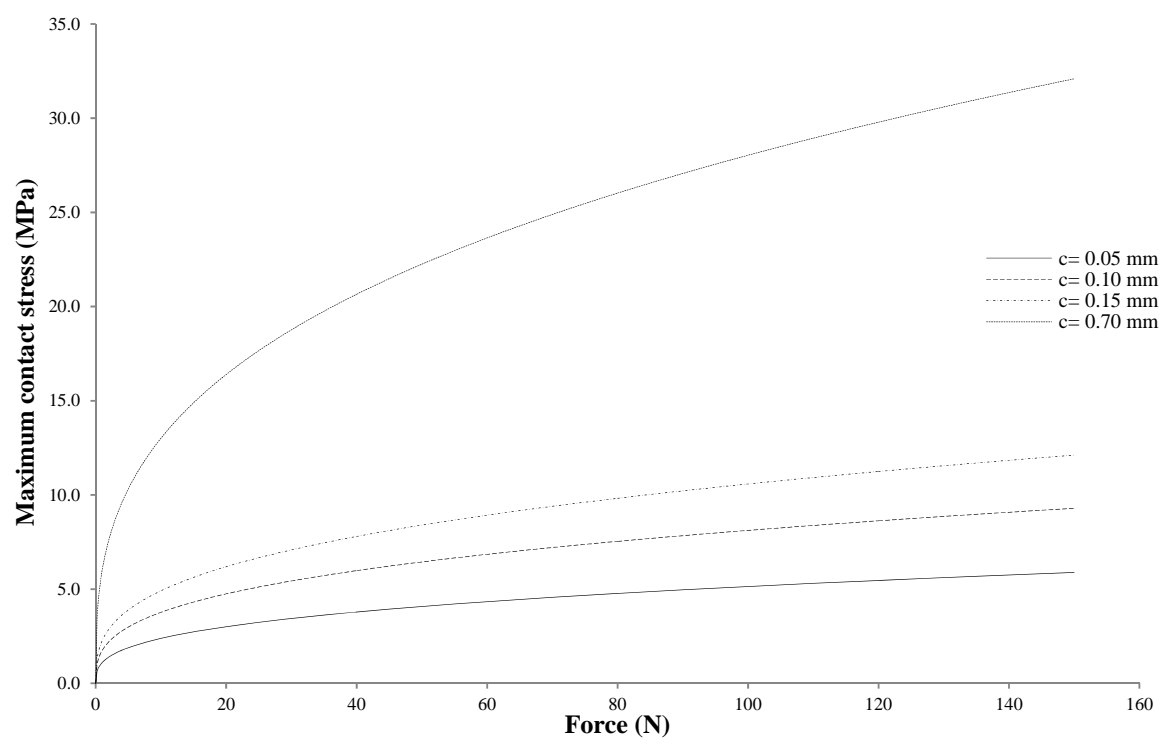

Fig. (2). Variation of maximum contact stress with force for radial clearance values of $0.05,0.10,0.15$ and $0.7 \mathrm{~mm}$. 


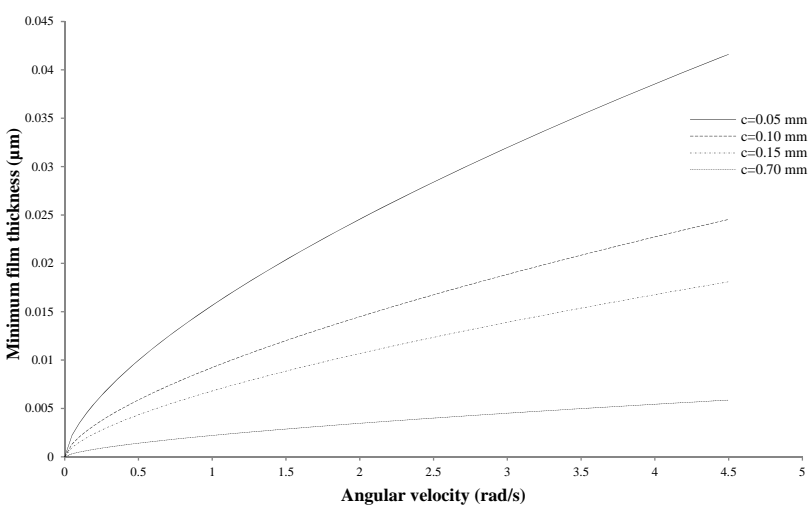

a)

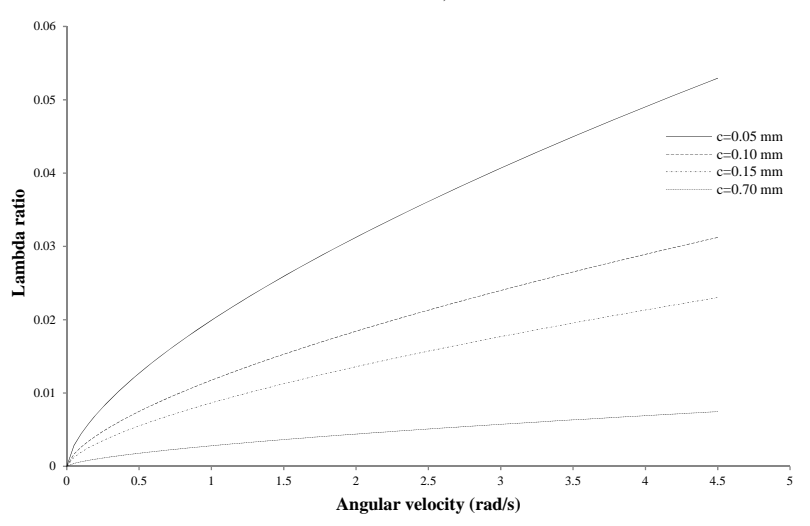

Fig. (3). a) Variation of minimum film thickness with angular velocity; b) Variation of Lambda ratio with angular velocity. Each figure is plotted for a cervical disc arthroplasty under $150 \mathrm{~N}$ load, using interstitial fluid as the lubricant, at radial clearance values of $0.05,0.1,0.15$ and $0.7 \mathrm{~mm}$.

\subsection{Lubrication Minimum Film Thickness}

Fig. (3a \& b) show the variation of minimum film thickness and lambda ratio, respectively, by incorporating different radial clearances. The predicted minimum film thickness was in the range 0 to $0.042 \mu \mathrm{m}$ and the corresponding lambda ratio range was from 0 to 0.052 . This indicates that the PEEK cervical discs will operate within a boundary lubrication regime across the whole range of angular velocities, under $150 \mathrm{~N}$ loading.

The effects of load level on the minimum film thickness and lambda ratio are displayed in Fig. (4a and 4b), respectively. They show that the loading level has a detrimental effect on both the minimum film thickness and the lambda ratio. Moreover, the obtained lambda ratio is always below unity and indicates boundary lubrication.

Fig. (5a \& b) show the variation of minimum film thickness and lambda ratio, respectively, when different lubricants are employed. The minimum film thickness can be enhanced by incorporating a more viscous lubricant; the lambda ratio can be increased in a similar manner. In spite of this, the lubrication regime is still boundary lubrication, regardless of the lubricant used.

\section{DISCUSSION}

This paper has predicted the likely contact stress and minimum film thickness between the bearing surfaces of a

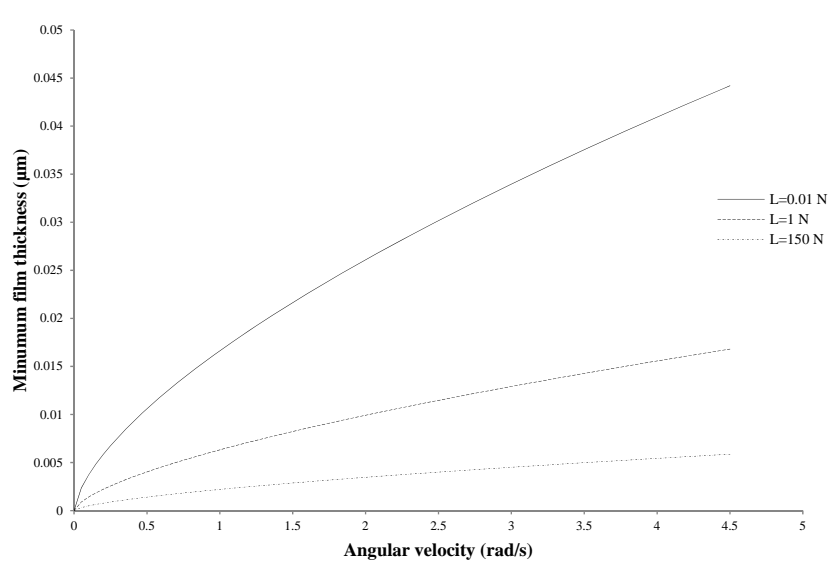

a)

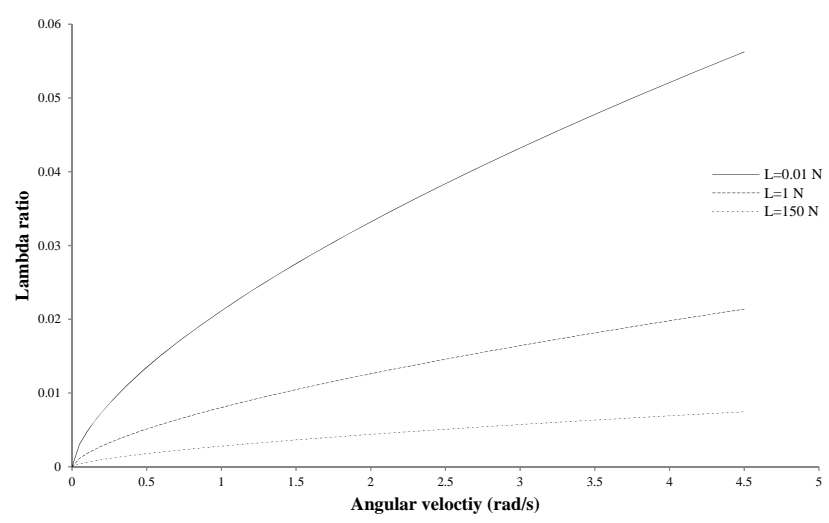

b)

Fig. (4). a) Variation of minimum film thickness with angular velocity; b) Variation of Lambda ratio with angular velocity. Each figure is plotted for a cervical disc arthroplasty at a radial clearance value of $0.7 \mathrm{~mm}$, using interstitial fluid as the lubricant, under three different load levels $0.01,1$ and $150 \mathrm{~N}$.

PEEK self-mating cervical disc. The calculated maximum Hertzian contact stress was in the range $5.9-32.1 \mathrm{MPa}$ under $150 \mathrm{~N}$ loading. Higher stresses were found for discs with a higher radial clearance. These values of stress are well below the yield strength of PEEK 450G under compression which is documented as $120 \mathrm{MPa}$ [25]. Furthermore, the fatigue strength of PEEK $450 \mathrm{G}$ with a crystallinity value of $22.5 \%$ was reported as $58.72 \mathrm{MPa}$, at one million cycles [26, 27]. It is predicted that the stress experienced by the contact surface of this disc is insufficient to result in material fatigue. Nevertheless, high cycle fatigue tests of at least 10 million cycles are still required to ensure the structural safety of cervical disc arthroplasty during long-term application [21]. Hertzain contact theory assumes that the contact surface is ideally smooth and frictionless and consequently the interaction force (i.e. adhesion force) between the contact surfaces within the contact zone was not considered. Although other elastic-smooth contact models, such as the Johnson-Kandall-Roberts model take the adhesion force into account [28], there would not be any significant difference between these two models, because the surface energy of PEEK is negligibly small at $0.044 \mathrm{~J} / \mathrm{m}^{2}[28,29]$.

The lubrication analysis assumes steady-state is achieved, under a given constant angular velocity. This is a simplified ideal situation to represent the motion of the neck, which 


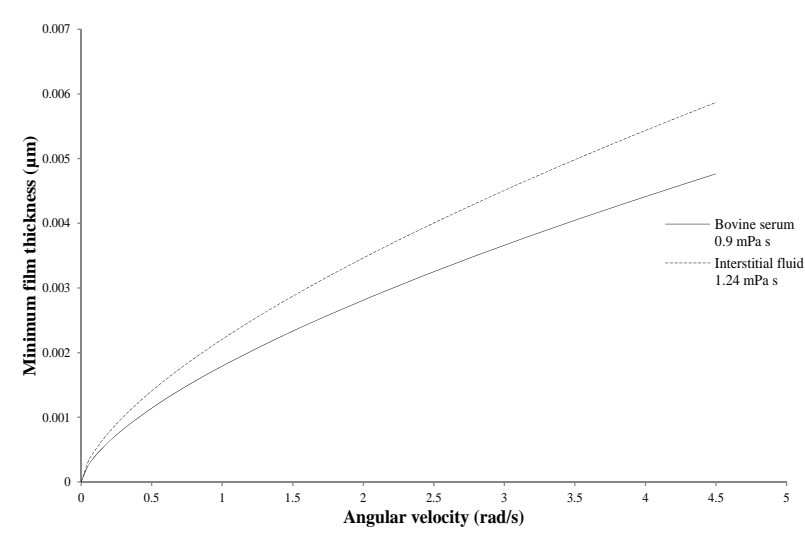

a)

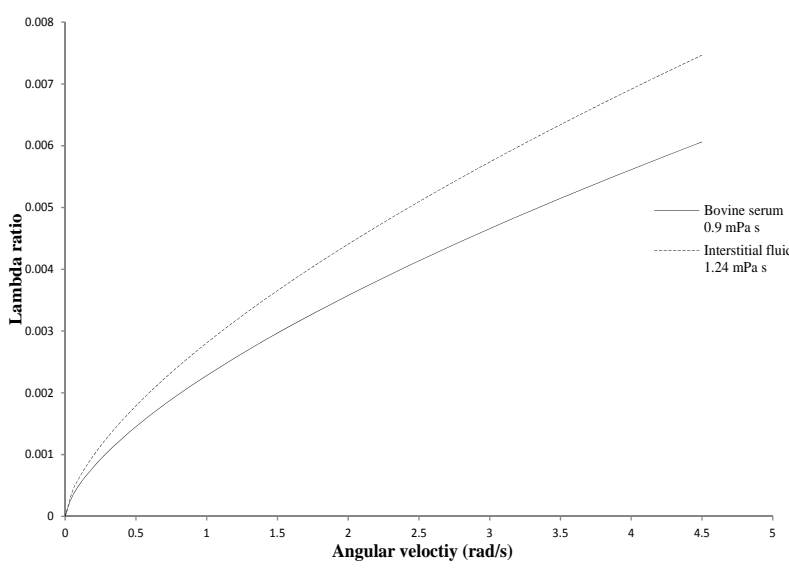

b)

Fig. (5). a) Variation of minimum film thickness with angular velocity; b) Variation of Lambda ratio with angular velocity. Each figure is plotted for a cervical disc arthroplasty at a radial clearance value of $0.7 \mathrm{~mm}$, under $150 \mathrm{~N}$ load, using two different lubricants bovine serum and interstitial fluid.

may not be achievable in practice. The intention of adopting this model is to ascertain the potential of cervical discs to operate under a fluid lubrication regime by altering its radial clearance or lubricant. The basic assumption of the elastohydrodynamic theory is that the lubricants (bovine serum and interstitial fluid) utilized are Newtonian fluids and there are no shear-thinning effects [16]. According to the obtained lambda ratio results, the PEEK cervical disc, for all parameters, will operate under a boundary lubrication regime, which means that there will be significant surface asperities contact and wear will occur. A previous study has shown that for lumbar disc arthroplasty most devices will also operate with a boundary lubrication regime [17]. According to the recent literature, the wear rate of PEEK self-mating cervical disc arthroplasty is reported as $1.4 \pm 0.4$ mg per million cycles; the historical cervical disc control (i.e. UHMWPE against $\mathrm{CoCrMo}$ ) has a wear rate of $1.0 \pm 0.4$ mg per million cycles [30].

There are concerns that debris generated as a result of wear may induce an adverse tissue response, such as chronic inflammation and osteolysis. Goodman proposed that the immune response to polymer particles is non-specific and macrophage mediated via the production of cytokines [31]. It is widely agreed that UHMWPE wear particles in the size range 0.1 to $1.0 \mu \mathrm{m}$ have been shown to be the most biological reactive $[11,32]$. Moreover, quantity, composition, and shape of the wear particles all play important roles in determining the host tissue response [33]. There are plenty of studies [32-34] that report on the biocompatibility of PEEK wear debris, however none focus on wear debris generated in cervical TDA. A recent in-vitro wear study pointed out that the wear particle size distribution of a PEEK-on-PEEK cervical disc was from 0.23 to $0.51 \mu \mathrm{m}$ with a mean roundness of 0.5 [30]. A more targeted host tissue response study is demanded to further ascertain the biocompatibility of PEEK wear debris generated from cervical total disc replacement.

Cervical disc arthroplasty is a relatively new technology and there is still much debate as to whether its performance is actually superior to that of fusion [4-7]. This study has discussed a new bearing material combination of PEEK against PEEK, but other devices have a longer record of use. Currently, there are three cervical disc arthroplasty (Prestige ST, Bryan, and ProDisc-C) undergoing a US FDA investigational device exemption trial [35]. Studies that have investigated the wear of other cervical disc arthroplasty are few. Anderson et al. [36] found that the Bryan disc had a wear rate of $1.2 \mathrm{mg}$ per million cycles and that this was satisfactory. Implantation of of a porous coated cervical disc arthroplasty into goats showed no inflammatory response from wear debris after six months implanted in the animals [37]. Lumbar disc arthroplasty have been studied in more detail [38-40], but a direct comparison with cervical discs is unwise due to the different motions and loads.

\section{CONCLUSIONS}

From this theoretical study, it can be confirmed that a PEEK based artificial cervical disc will operate under a boundary lubrication regime, with the generation of wear debris likely. The maximum contact stress was found to be 32.1 MPa, but this is less than either the compressive yield strength or fatigue strength of PEEK 450G.

\section{CONFLICT OF INTEREST}

None declared.

\section{ACKNOWLEDGEMENTS}

We thank Dr William A. Murray for the help with operating the Taylorsurf-120L and DEA-Swift equipment.

\section{GLOSSARY}

$\begin{array}{lll}R_{1} & = & \text { Radius curvature of ball component. } \\ R_{2} & = & \text { Radius curvature of socket component. } \\ c & = & \begin{array}{l}\text { Radial clearance equals to the difference } \\ \text { between the } \mathrm{R}_{2} \text { and } \mathrm{R}_{1} .\end{array} \\ P_{\max }= & \text { Maximum contact stress. } \\ F & =\quad \text { Applied force. } \\ E^{\prime} & =\quad \begin{array}{l}\text { Equivalent elastic modulus for the two } \\ \text { bearing material. }\end{array} \\ E & = & \text { Equivalent radius for ball and socket. } \\ v & = & \text { Youth's modulus of the material. } \\ h_{\min } & =\quad \text { Poisson's ratio of the material. }\end{array}$


$\mu \quad=\quad$ Viscosity of the lubricant.

$u=$ Entrance velocity of the disc.

$E^{*} \quad=\quad$ Equivalent modulus of elasticity.

$\lambda=$ Lambda ratio.

$\sigma \quad=\quad$ Compound surface roughness.

\section{REFERENCES}

[1] S. M. Kurtz and A. A. Edidin, "The Basic Tools and Terminology of Spine Treatment," In: Spine Technology Handbook, S. M. Kurtz and A. A. Edidin, Eds. Academic Press: Burlington, 2006, pp. 1-9.

[2] H. A. Guerin and D. M. Elliott, "Structure and Properties of Soft Tissues in the Spine," In: Spine Technology Handbook, S. M. Kurtz and A. A. Edidin, Eds. Academic Press: Burlington, 2006, pp. 35-62.

[3] S. M. Kurtz, "Total Disc Arthroplasty," In: Spine Technology Handbook, S. M. Kurtz and A. A. Edidin, Eds. Academic Press: Burlington, 2006, pp. 303-370.

[4] D. B. Murrey, M. E. Janssen, S. M. Odum, J. R. Gottlieb, L. R. Spector, and B. V. Darden, "Two-Year Results of a Randomized Controlled Clinical Trial Comparing ProDisc-C and Anterior Cervical Discectomy and Fusion," $S A S$ J., vol. 2, pp. 76-85, June 2008.

[5] A. S. Hilibrand and M. Robbins, "Adjacent segment degeneration and adjacent segment disease: the consequences of spinal fusion?," Spine J., vol. 4, pp. S190-S194, Nov 2004.

[6] J. T. Robertson, S. M. Papadopoulos, and V. C. Traynelis, "Assessment of adjacent-segment disease in patients treated with cervical fusion or arthroplasty: a prospective 2-year study," $J$. Neurosurg Spine, vol. 3, pp. 417-423, Dec 2005.

[7] R. B. Delamarter, D. Murrey, M. E. Janssen, J. A. Goldstein, J. Zigler, B. K. B. Tay, and B. Darden II, "Results at 24 months from the prospective, randomized, multicenter Investigational Device Exemption trial of ProDisc-C versus anterior cervical discectomy and fusion with 4-year follow-up and continued access patients," SAS J., vol. 4, pp. 122-128, Dec 2010.

[8] N. Hallab, "Intervertebral disc joint replacement technology," In: Joint Replacement Technology, P. A. Revell, Ed. Woodhead Publishing Limited: Cambridge, 2008, pp. 515-544.

[9] A. Zeh, M. Planert, G. Siegert, P. Lattke, A. Held, and W. Hein, "Release of Cobalt and Chromium Ions Into the Serum Following Implantation of the Metal-on-Metal Maverick-Type Artificial Lumbar Disc (Medtronic Sofamor Danek)," Spine, vol. 32, pp. 348352, Feb 2007.

[10] S. A. Brown, "Synthetic Biomaterials for Spinal Applications," In: Spine Technology Handbook, Kurtz S.M. and A. A. Edidin, Eds. Academic Press: Burlington, 2006, pp. 11-33.

[11] E. Ingham and J. Fisher, "The role of macrophages in osteolysis of total joint replacement," Biomaterials, vol. 26, pp. 1271-1286, Apr 2005.

[12] S. M. Kurtz and J. N. Devine, "PEEK biomaterials in trauma, orthopedic, and spinal implants," Biomaterials, vol. 28, pp. 48454869, Nov 2007.

[13] I.G. Goryacheva, "Contact Mechanics in Tribology," Kluwer Academic Publishers: Boston, 1998.

[14] G. R. Johnson, "Biomechanics of joints," In Joint Replacement Technology, P. A. Revell, Ed. Woodhead Publishing Limited: Cambridge, 2008, pp. 1-30.

[15] T. J. Joyce, "Biopolymer Tribology," in Polymer Tribology, S. K. Sinha and B. J. Briscoe, Eds. Imperial College Press: London, 2009, pp. 227-266.

[16] L. Mattei, F. Di Puccio, B. Piccigallo, and E. Ciulli, "Lubrication and wear modelling of artificial hip joints: a review," Tribol Int, vol. 44, pp. 532-549, May 2011.

[17] A. Shaheen and D. E. T. Shepherd, "Lubrication regimes in lumbar total disc arthroplasty," Proc. Inst. Mech. Eng. H., vol. 221, pp. 621-627, Jan 2007.

[18] J. P. Clewlow, T. Pylios, and D. E. T. Shepherd, "Soft layer bearing joints for spine arthroplasty," Mater Des., vol. 29, pp. 1981-1985, Dec 2008.

[19] S. A. Wenzel and D. E. T. Shepherd, "Contact stresses in lumbar total disc arthroplasty," Bio-Med Mater. Eng., vol. 17, pp. 169-173, Jan 2007.
[20] P. Salvia, O. Champagne, V. Feipel, M. Rooze, and D. Z. de Beyl, "Clinical and goniometric evaluation of patients with spasmodic torticollis," Clin. Biomech., vol. 21, pp. 323-329, May 2006.

[21] "ISO 18192-1:2011. Implants for surgery - Wear of total intervertebral spinal disc prostheses Part 1: Loading and displacement parameters for wear testing and corresponding environmental conditions for test ISO International Standards," Geneva: International Organization for Standarization, 2011.

[22] U. Windberger, A. Bartholovitsch, R. Plasenzotti, K. J. Korak, and G. Heinze, "Whole blood viscosity, plasma viscosity and erythrocyte aggregation in nine mammalian species: reference values and comparison of data," Exp. Physiol., vol. 88, pp. 431440, May 2003.

[23] Y. Zurovsky, G. Mitchell, and J. Hattingh, "Composition and Viscosity of interstitial fluid of rabbits," Exp. Physiol., vol. 80, pp. 203-207, Sept 1994.

[24] Z. Jin, J. B. Medley and D. Dowson, "Fluid film lubrication in artificial hip joints," In: Tribological Research and Design for Engineering Systems, D. Dowson, M. Priest, G. Dalmaz, A. A. Lubrecht, Eds. Elsevier: Amsterdam, 2003, pp. 237-256.

[25] "Victrex PEEKTM 450G datasheet," Victrex plc, 2009. Available from http://www.victrex.com/en/victrexlibrary/datasheets/datasheets.php.

[26] S. M. Tang, P. Cheang, M. S. AbuBakar, K. A. Khor, and K. Liao, "Tension-tension fatigue behavior of hydroxyapatite reinforced polyetheretherketone composites," Int. J. Fatigue., vol. 26, pp. 4957, Jan 2004.

[27] M. S. Abu Bakar, M. H. W. Cheng, S. M. Tang, S. C. Yu, K. Liao, C. T. Tan, K. A. Khor, and P. Cheang, "Tensile properties, tensiontension fatigue and biological response of polyetheretherketonehydroxyapatite composites for load-bearing orthopedic implants," Biomaterials, vol. 24, pp. 2245-2250, June 2003.

[28] K. M. Nikolai and V. K. Alexander, "Adhesion and Friction of Polymers," in Polymer tribology, K. S. Sujeet and J. B. Brian, Eds. Imperial College Press: London, 2009, pp. 3-37.

[29] S. Zhang, F. Awaja, N. James, D. R. McKenzie, and A. J. Ruys, "Autohesion of plasma treated semi-crystalline PEEK: Comparative study of argon, nitrogen and oxygen treatments," Colloids Surf. A Physicochem Eng. Asp., vol. 374, pp. 88-95, Jan 2011.

[30] T. M. Grupp, H. J. Meisel, J. A. Cotton, J. Schwiesau, B. Fritz, W. Blömer, and V. Jansson, "Alternative bearing materials for intervertebral disc arthroplasty," Biomaterials, vol. 31, pp. 523531, Jan 2010.

[31] S. B. Goodman, "Wear particles, periprosthetic osteolysis and the immune system," Biomaterials, vol. 28, pp. 5044-5048, Dec 2007.

[32] G. I. Howling, H. Sakoda, A. Antonarulrajah, H. Marrs, T. D. Stewart, S. Appleyard, B. Rand, J. Fisher, and E. Ingham, "Biological response to wear debris generated in carbon based composites as potential bearing surfaces for artificial hip joints," $J$ Biomed Mater Res, vol. 67, pp. 758-764, Nov 2003.

[33] S. Utzschneider, F. Becker, T. M. Grupp, B. Sievers, A. Paulus, O Gottschalk, and V. Jansson, "Inflammatory response against different carbon fiber-reinforced PEEK wear particles compared with UHMWPE in vivo," Acta. Biomater., vol. 6, pp. 4296-4304, Nov 2010.

[34] C.H. Rivard, S. Rhalmi, C. Coillard, "In vivo biocompatibility testing of PEEK polymer for a spinal implant system: a study in rabbits," J. Biomed. Mater. Res., vol. 62, pp. 488-498, Dec 2002.

[35] C.D. Upadhyaya, J. C. Wu, G Trost, R. W. Haid, V. C. Traynelis, B. Tay, D. Coric and P. V. Mummaneni, "Analysis of the three United States Food and Drug Administration investigational device exemptioncervical arthroplasty trials Clinical article," $J$. Neurosurg. Spine, vol. 16, pp. 216-228, Mar 2012.

[36] P.A. Anderson, J.P. Rouleau, V.E. Bryan and C.S. Carlson, "Wear analysis of the Bryan cervical disc prosthesis," Spine, vol. 28, pp. S186-S194, Oct 203.

[37] P. C. McAfee, B. Cunningham, A. Dmitriev, N. B. Hu, S. W. Kim, A. Cappuccino and L. Pimenta, "Cervical disc replacement porous coated motion prosthesis - a comparative biomechanical analysis showing the key role of the posterior longitudinal ligament," Spine, vol. 28, pp. S176-S185, Oct 2003.

[38] P. Moghadas, A. Mahomed, D. W. L.Hukins, D. E. T. Shepherd, "Friction in metal-on-metal total disc arthroplasty: effect of ball radius," J. Biomech., vol. 45, pp. 504-509, Feb 2012 
[39] R. Vicars, P. J. Hyde, T. D. Brown, J. L. Tipper, E. Ingham, J. Fisher, R. M. Hall, "The effect of anterior-posterior shear load on the wear of ProDisc-L TDR," Eur. Spine J., vol. 19, pp. 1356-1362, Aug 2010.
[40] P. E. Pare, F. W. Chan, M. L. Powell, "Wear characterization of the A-MAV (TM) anterior motion replacement using a spine wear simulator," Wear, vol. 263, pp. 1055-1059, Sep 2007.

Received: January 27, 2012

Revised: March 29, 2012

Accepted: March 29, 2012

(C) Xin et al.; Licensee Bentham Open.

This is an open access article licensed under the terms of the Creative Commons Attribution Non-Commercial License (http://creativecommons.org/licenses/by-nc/3.0/) which permits unrestricted, non-commercial use, distribution and reproduction in any medium, provided the work is properly cited. 